\section{REGARDING CO-PAYMENTS}

To the editor: It was fascinating to read the latest debate in the CFEM regarding copays. ${ }^{1}$ Of particular note was the choice of using a Canadian viewpoint in support of copays and an American viewpoint against them. Dr. Howlett's opening remark is in agreement with the principle behind Medicare - that the provision of healthcare services should be based on need regardless of the ability to pay. However, he continues by implying that "mediocrity" is good enough for those who cannot pay and that those who can afford to should be able to pay for better care and in doing so, widen the gap of quality service. This does not follow the philosophy of the Canadian Medicare system. Dr. Howlett also suggests that "extra services" (i.e., pharmaceuticals, and so forth) already widen the gap. This, in fact, is very true. That is why many advocates and supporters of public healthcare continue to push for improvements to our existing system, which would include expanding the number of services covered and implementing a universal pharmacare plan.

Copayments in healthcare - even in small amounts - have been proven to increase health inequity, and vulnerable populations are the most affected. ${ }^{2}$ We have seen this as far back as 1968 in Saskatchewan when copayments as small as $\$ 1.50$ (\$10.70 in current dollars) decreased the utilization of general practitioners by the poor by $14 \% .^{3}$ An increase in copays for prescription drugs in Quebec meant reductions in the use of essential medicines as well as a higher rate of adverse events and emergency room visits associated with the reductions. ${ }^{4}$ Copays create a barrier to good holistic primary care. We agree the time has come to evolve Medicare services to serve modern healthcare needs. Let's complete what Tommy Douglas started and create a National Pharmacare program and move to include allied health services in Medicare coverage. This will ultimately use tax dollars smartly and efficiently to make services accessible and universal regardless of the ability to pay while promoting holistic health and wellbeing for all of our citizens.

\section{Sarah Gander, FRCPC}

Faculty of Medicine, Department of Pediatrics, Dalhousie University, Saint John, NB.

\section{REFERENCES}

1. Hoffman GJ, Hoffman JR, Howlett M, Atkinson P. CFEM Debate Series: \#Copayment - Medical insurance is for non-routine events. C7EM 2018;20 (1):16-20. doi:10.1017/cem.2017.411.

2. Keane M. Copayments and the evidence-base paradox. Med 7 Aust 2015;202:68-70.

3. Beck R. The effects of co-payment on the poor. 7 Hum Resour 1974;9: 129-42.

4. Tamblyn R, Laprise R, Hanley JA, Abrahamowicz M, Scott S, Mayo N, Hurley J, Grad R, Latimer E, Perreault R, McLeod P, Huang A, Larochelle P, Mallet L. Adverse events associated with prescription drug cost-sharing among poor and elderly persons. $7 A M A 2001 ; 285$ : 421-9. 